\title{
Bed Rest
}

National Cancer Institute

\section{Source}

National Cancer Institute. Bed Rest. NCI Thesaurus. Code C45985.

Confinement of an individual to bed for therapeutic reasons. 